\title{
4 \\ COLOMBIA: EL REPRISE COMO PROTAGONISTA EN TIEMPOS DE PANDEMIA
}

DOI: https://doi.org/10.7764/obitel.21.S.6

\begin{abstract}
Autores:
Fernando Aranguren Díaz https://orcid.org/0000-0001-5565-4536, Borys Bustamante Bohórquez https://orcid.org/0000-0001-7986-144, Hernán Javier Riveros Solórzano: https://orcid.org/0000-0002-1185-7603
\end{abstract}

Equipo:

Diana María Lozano Prat, María Teresa Garzón Carreño, Gloria Yuliana Sepúlveda, Daniela Buitrago Pastrana, Juan Felipe Nieto Molina, Zulma Velandia Velandia, Olga Milena Forero Contreras

\section{Introducción}

El año 2020 fue completamente atípico a nivel global y seguramente pasará a la historia como un periodo de crisis, incertidumbres y profundos cambios en los hábitos de la vida y las sociedades en el mundo. Así, tras la declaratoria de pandemia en relación con el virus Sars Cov 2 y la enfermedad COVID 19, el globo enfrentó un reto inesperado representado en la declaratoria de cuarentenas, confinamientos y todo un conjunto de medidas de salud pública en medio de la angustia ante el aumento de ocupación de Unidades de Cuidado Intensivo, el colapso hospitalario y, pese a los altísimos niveles de avances tecnológicos actuales, un amplio desconocimiento de medidas para la contención, prevención y manejo del virus. En este marco, en el caso colombiano, 
a partir del primer caso, detectado el 6 de marzo de 2020, entró en operación un sistema de medidas encabezadas por diferentes decretos y regulaciones gubernamentales como los decretos 457 del 22 de marzo de 2020, el 637 del 6 de mayo de 2020 y el 417 del 17 de marzo de 2020, en las cuales no solo se declaró el Estado de Emergencia a nivel nacional sino que también se generaron diferentes estrategias como el confinamiento generalizado, las restricciones a la movilidad y al mismo tiempo se suspendieron diferentes actividades productivas, educativas y sociales.

La pantalla chica no fue ajena a la situación, por el contrario, las parrillas televisivas empezaron a poblarse de informativos de larga duración y, al mismo tiempo, la ficción se convirtió en la compañera de los hogares colombianos, así como una especie de escape de los conteos de fallecidos y contagiados reportados a diario. De igual modo, plataformas como Netflix, Amazon Prime y la llegada al final del año Disney + junto con sistemas como los de HBO + y espacios como Claro Video, también se convirtieron en alternativas para acompañar los momentos de angustia e incertidumbre de las gentes confinadas en sus casas. Por ello, posterior al debate sobre porcentaje de pantalla de producciones nacionales, que permitió la aparición de los reprises como protagonistas del prime time no solo por apelar a la nostalgia, sino también por esa dosis de humor, ingenio y entretenimiento que permitía por momentos dejar de lado la complejidad de una realidad epidemiológica y social en la que junto al crecimiento de los picos de la enfermedad, también proliferaban banderas rojas en las ventanas como símbolo de la crisis económica de los más vulnerables. Así, el 2020 se presentó en Colombia como un año de encierro, como en el resto del mundo, pero también, en el caso de la ficción televisiva, un periodo para revisitar las producciones de otros tiempos, tanto en la pantalla chica como en los sistemas de streaming, generándose fenómenos tan curiosos como que, al mismo tiempo, Pasión de Gavilanes fuera la ficción más vista tanto en televisión nacional como en Netflix. Y en paralelo a esto, el florecimiento de nuevas producciones y series 
web como refugio para actores, actrices e incluso un nuevo escenario para el teatro y una industria como la audiovisual que, junto con otras, entraba en un angustiante receso.

\section{El contexto audiovisual de Colombia en 2020 \\ 1.1. La televisión abierta en Colombia}

La televisión abierta en Colombia se compone por cinco canales de orden nacional distribuidos así:

Cuadro 1. Cadenas/Canales Nacionales de Televisión Abierta en Colombia

\begin{tabular}{|c|c|}
\hline Canales privados (3) & Canales públicos (2) \\
\hline Caracol & Señal Colombia \\
\hline R.C.N. & Canal Institucional \\
\hline Canal Uno & \\
\hline \multicolumn{2}{|c|}{ TOTAL CANALES $\mathbf{= 5}$} \\
\hline
\end{tabular}

Fuente: Obitel Colombia

En tiempos de pandemia nuevamente Caracol asume una condición de liderazgo entre las audiencias, reforzado por espacios informativos y la abundancia de reprises que lograron posicionarse de manera principal en el prime time durante el 2020.

\section{Gráfico 1. Rating y Share de TV por Emisora}

\begin{tabular}{|l|c|c|l|c|}
\hline Emisora & $\begin{array}{c}\text { Aud. } \\
\text { Dom }\end{array}$ & $\mathbf{\%}$ & Emisora & $\begin{array}{c}\text { Share } \\
(\mathbf{\%})\end{array}$ \\
\hline Caracol & 14,5 & 45,1 & Caracol & 51,6 \\
\hline R.C.N. & 11,3 & 35,1 & R.C.N. & 30,4 \\
\hline Canal Uno & 3,1 & 9,6 & Canal Uno & 10,6 \\
\hline Señal & 2,9 & 9,0 & Señal & 3,32 \\
\hline Institucional & 0,4 & 1,2 & Institucional & 0,75 \\
\hline TOTAL & $\mathbf{3 2 , 2}$ & $\mathbf{1 0 0}$ & & $\mathbf{9 6 , 6}$ \\
\hline
\end{tabular}

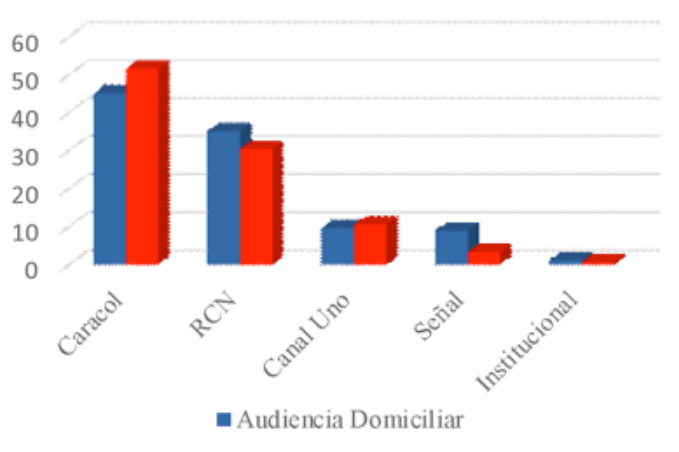

Fuente: Obitel Colombia / Kantar Ibope Media Colombia 
El gráfico anterior evidencia el crecimiento considerable tanto de rating como de share en el caso de Caracol frente a $\mathrm{RCN}$, principalmente por la alta presencia de reprises y la capacidad de atraer audiencias logrado por los espacios informativos, principalmente el noticiero, el cual aumentó la duración de sus emisiones en tiempos de pandemia. De esta manera, el espacio noticioso de la noche no solo se convirtió en el programa de mayor audiencia, sino también en el elemento de arrastre hacia un prime time copado por producciones que fueron éxito en otros tiempos como Pasión de Gavilanes y Pedro El Escamoso.

Gráfico 2: Géneros y Horas Transmitidos en la Programación de TV.

\begin{tabular}{|c|c|c|}
\hline Géneros Transmitidos & $\begin{array}{c}\text { Horas de } \\
\text { Exhibición }\end{array}$ & $\mathbf{\%}$ \\
\hline Ficción & $21.317: 30$ & 32,8 \\
\hline Información & $20.870: 30$ & 32,2 \\
\hline Deporte & $5.237: 20$ & 8,2 \\
\hline Entretenimiento & $10.355: 30$ & 15,9 \\
\hline Religioso & $630: 30$ & 0,9 \\
\hline Político & $770: 20$ & 1,1 \\
\hline Educativo & $870: 20$ & 1,3 \\
\hline Otros & $4.987: 25$ & 7,6 \\
\hline TOTAL & $\mathbf{6 5 . 0 3 6 : 2 5}$ & $\mathbf{1 0 0}$ \\
\hline
\end{tabular}

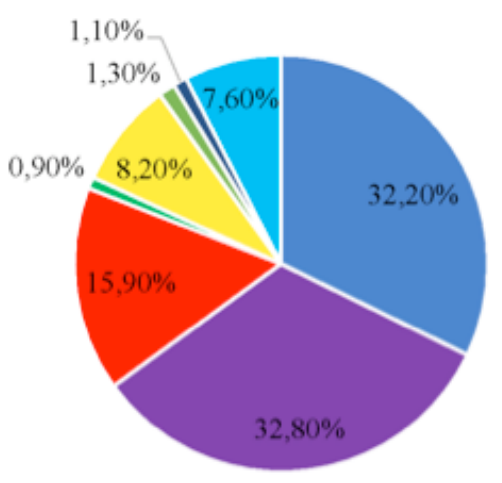

- Información

- Ficción

- Entretenimiento

- Religioso

- Deporte

- Educativo

- Politico

- Otros

Fuente: Obitel Colombia 
En la oferta televisiva del 2020, producto de la situación global surgida por la pandemia, estuvo protagonizada por los informativos y las ficciones. Esto toda vez que los eventos deportivos, musicales y culturales no se realizaron durante gran parte del año, dejando el espacio televisivo a la ficción y sobre todo a espacios de información que se convirtieron en los acompañantes de una gran porción del día de las audiencias. Esto se vio reflejado en el aumento de las emisiones noticiosas a convertirse en espacios de más de tres horas de duración.

\subsection{La TV de pago y plataformas VoD en Colombia}

La situación mundial vivida durante el 2020, en donde las cuarentenas extendidas fueron un fenómeno común, si no total, las plataformas de televisión paga y videos por demanda se convirtieron en la principal apuesta de entretenimiento de los consumidores. Es así como en Colombia, según informe desarrollado por Sherlock Communications sobre el consumo de estas en América Latina, el 48\% de colombianos se suscribieron a una de las plataformas de streaming disponibles, mientras que el $20 \%$ decidió acceder a dos de estos servicios. La muestra deja ver el aumento de estos sistemas de entretenimiento que, a pesar de las dificultades económicas causadas por la pandemia, resultan un producto de consumo masivo indispensable en los hogares.

Agregado a este fenómeno, se encuentran las posibilidades de plataformas de contenido exclusivo ofrecidas por los cable operadores, principalmente Claro Video, servicio que permite a todos los suscriptores de esta compañía, acceder a series y películas que no son ofrecidas en el servicio tradicional. Por otra parte, para el 2020 se destaca la llegada de la plataforma Disney + a Colombia, lo cual generó una alta demanda de suscripciones bajo la premisa de encontrar contenido exclusivo de entretenimiento desde los clásicos hasta las series desarrolladas exclusivamente para este espacio. Amazon Prime 
por otra parte se extendió como otra de las opciones codiciadas, sin embargo, Netflix continúa siendo la plataforma preferida en el país.

\section{Cuadro 2. Cadenas de televisión de pago en Colombia}

\begin{tabular}{|l|}
\hline \multicolumn{1}{|c|}{$\begin{array}{c}\text { vistas en } \mathbf{2 0 2 0} \\
\text { vadenas de TV Pago más }\end{array}$} \\
\hline 1) FOX (Series Peliculas), \\
2) TNT (Series Peliculas) \\
3) SPACE (Series Películas) \\
4) HBO (Series películas) \\
5) GOLDEN (Series películas) \\
6) FOX Sports (Deportes) \\
7) ESPN (Deportes) \\
8) WIN Sports (Deportes) \\
9) NTN 24 (Noticias) \\
10) Cable noticias (Noticias) \\
\hline
\end{tabular}

Fuente: Obitel Colombia

En Colombia se presenta una situación muy particular y es que se destaca el uso de canales incluidos en los paquetes de pago, principalmente aquellos relacionados con contenidos de ficción y deportivos. Esto tiene una relación directa con el gusto que hay por el contenido deportivo, de fútbol principalmente, de parte de los colombianos. Durante el 2020 se destacó la polémica causada por el canal WinSports+ que se convirtió en el único canal en donde se transmiten todos los partidos de la liga profesional de fútbol colombiano, pues, en general los costos se consideraron altos de parte de los usuarios y se entró en la discusión de aquello que debería hacer parte de la televisión abierta. 


\section{Cuadro 3. El VoD en Colombia}

\begin{tabular}{|l|c|}
\hline $\begin{array}{c}\text { Principales plataformas de VoD } \\
\text { activas en 2020 }\end{array}$ & Total \\
\hline $\begin{array}{l}\text { Netflix, Disney+, Prime (Amazon), } \\
\text { HBOGo (Warner Media), FOX+ } \\
\text { (Disney). }\end{array}$ & $\mathbf{5}$ \\
\hline & \\
\hline
\end{tabular}

Fuente: Obitel Colombia

Aun cuando las anteriores son las 5 plataformas principales en Colombia, cable operadores como Claro con Claro Video y otras grandes cadenas nacionales como Caracol Play ofrecen también sus servicios VoD. Sumado a ello, es de destacar la propuesta de carácter público que vienen forjándose desde 2015: RTVC Play.

Durante el año 2020 en Colombia se mantuvo la curva de ascenso en el consumo de plataformas de streaming, principalmente de la plataforma Netflix, la cual ha tenido una acogida tal que se ha mantenido en el primer lugar de consumo en el país, pero además ha conllevado la constitución de nuevas dinámicas de mercadeo, incluyendo incluso la posibilidad de consumir este servicio en modalidad prepago a través de tarjetas que se venden en diferentes tiendas de tecnología y almacenes de cadena. Por otra parte, aunque no existen fuentes oficiales sobre esta modalidad, existen en redes sociales posibilidades de comercialización de cuentas informales en las cuales los costos de acceso a esta y otras plataformas de streaming son muchísimo menores.

Dentro de las dinámicas propias del país también se destaca que existen cadenas de televisión abierta que ofrecen servicios adicionales a los cuales se puede acceder como servicio pago, tal es el caso del sistema VOD de Caracol Play la cual hace parte del canal Caracol 
Televisión que funciona como canal abierto. Se suma a esta modalidad, aquella desde la cual los consumidores tienen la posibilidad de acceder a servicios adicionales como las cadenas de HBO y FOX + como parte de los beneficios por adquirir planes de televisión paga, un ejemplo de esto es Claro Video, plataforma que funciona como beneficio para los usuarios de la televisión paga de la compañía Claro.

\subsection{Productoras independientes de ficción televisiva}

El fenómeno presentado durante la cuarentena del 2020 en el mundo deja una tendencia en el comportamiento de estas compañías que, dentro de las nuevas posibilidades, han avanzado hacia la elaboración de producciones con una carga de creatividad y nuevas maneras de desarrollar el proceso. Dentro de las tendencias que se evidenciaron en el caso colombiano, se encuentran aquellas desde las cuales las productoras independientes desarrollaron proyectos relacionados con la elaboración de piezas aptas para la emisión a través de plataformas gratuitas, especialmente YouTube. Surgieron ideas que permitían evidenciar en la pantalla, aquellas situaciones de las que las familias estaban siendo parte en el día a día de este tiempo tan particular, muestras de ello se encuentran en series como: "Una familia en cuarentena" o "Aisla2 en cuarentena" y productos desarrollados por algunos Youtubers enfocados en este tema.

De este ejercicio particular, también surgieron producciones que, aprovechando el momento histórico, en conjunto entre grandes compañías y productoras, trabajaron en miniseries para ser emitidas en diferentes medios digitales y desde los cuales se publicitaba la marca, pero, de igual manera, se mantenía la dinámica narrativa de las producciones de ficción. Un caso para resaltar de este ejercicio es la serie "Vidas posibles", emitida en su propia página web como resultado entre la marca francesa de vehículos Renault y la productora Fox Colombia. A la luz del trabajo creativo, resultado de la cuarentena, se 
puede deducir que aunque las afectaciones al gremio de la televisión en general fueron muy negativas, existieron ejemplos de nuevas dinámicas que ambientaron el proceso y permitieron dar vida a producciones diferentes y entretenidas para el público.

\subsection{Fuentes de financiamiento del sector audiovisual}

El 2020 fue un año especialmente complicado para todos los sectores económicos afectados directamente por las cuarentenas extendidas y los efectos de la pandemia mundial, sin embargo, algunos sectores también resultaron favorecidos dadas las condiciones de confinamiento en las que se encontraron los consumidores. Un claro ejemplo de esta condición es el sector de televisión por suscripción, que según el data flash emitido el 12 de abril de 2021por la Comisión de Regulación de Comunicaciones (CRC), tuvo un fuerte impulsó al alza en el consumo de sus servicios, "durante el año 2020 los ingresos asociados al servicio de televisión por suscripción alcanzaron los $\$ 3,26$ billones, lo que representó un crecimiento de 2,13\% con respecto al año 2019. Por su parte, los suscriptores de este servicio llegaron a 6,06 millones, presentando un aumento de más de 131 mil suscriptores al compararlo con el año 2019”. Aunque estas cifras aplican exclusivamente para planes básicos, se evidencia el aumento en los accesos a estos servicios. Finalmente, el 6,56\% de inversión realizado en inscripciones de televisión paga, corresponden a los servicios premium.

De otra parte, el informe de Ibope respecto al consumo de televisión en Colombia, refleja que durante el año 2020 se realizó una inversión de \$4.613.625.671 en publicidad en los canales de televisión abierta, llevándose el primer lugar de inversión en publicidad la emisión de prime time de Caracol Televisión con un valor de $\$ 270.891 .529$. Otras fuentes de financiación de la televisión colombiana están relacionadas con el acceso a los sistemas de contenido 
exclusivo de los canales de televisión abierta y las nuevas tendencias de producciones relacionadas con ficción realizadas en alianza entre grandes marcas comerciales y productoras que toman ventaja de la situación específica de la pandemia.

\subsection{Políticas de comunicación}

El 20 de enero de 1995, entraba en vigencia la ley 182 de 1995 por la cual se reglamentaba el servicio de la televisión y se formulaban políticas para su desarrollo. No obstante, por la coyuntura generada por el covid-19, las cadenas nacionales se vieron obligadas a cancelar y detener los rodajes y producciones, ante las medidas de confinamiento decretadas por el Gobierno Nacional. Para agravar la situación, el 4 de abril de 2020 se expide el Decreto 516 del 4 de abril del 2020, en el que se redujo la cuota de pantalla de programación nacional al 20\%. La adición de un segundo parágrafo al artículo 33 de la ley 182 de 1995, estableció que, de acuerdo con la duración del estado de emergencia los porcentajes mínimos de programación nacional sería de $20 \%$ en la franja prime time, una reducción considerable para una industria sometida a los rigores de la pandemia.

La anterior situación, llevó al sector audiovisual del país a preguntarse ¿por qué en tiempos de emergencia, cuando el trabajo escasea, se reduce el apoyo e incentivo a la producción audiovisual del país? El descontento no se hizo esperar y organizaciones como el ACA (Asociación Colombiana de Actores) y la ACTV (Asociación Colombiana de Trabajadores de la Industria Audiovisual), manifestaron que la reducción de participación en la cuota de pantalla a un 20 $\%$, reducía no sólo las producciones nacionales, sino los ingresos que recibían libretistas, productores y actores en tiempos de confinamiento por la retrasmisión de producciones nacionales, gracias a leyes como la Pepe Sánchez o Fanny Mikey. Entre los diferentes gremios del sector audiovisual se promovió un descontento generalizado, contra el 
decreto emitido por el Ministerio de las Tecnologías de la Información y la Comunicación (MinTIC) en cabeza de la ministra Sylvia Constaín, quien manifestó que la medida tomada era temporal, sin embargo, para los diferentes gremios la medida desconocía las necesidades del sector. Fue así, que nació un movimiento contra el programa de la "economía naranja" del gobierno de Duque, que bajo el hagshtag \#MuchaPantallaPocaNaranja movilizó a diferentes actores, productores y libretistas del país. ${ }^{1}$ Esto condujo finalmente a que se mantuviera la llamada cuota de pantalla, lo que se tradujo en la aparición de un numeroso conjunto de reprises que se convirtieron en los protagonistas del prime time.

\subsection{Infraestructura de conectividad digital y móvil}

Entre los cambios tecnológicos que vivió el país durante las últimas décadas, se encuentra la implementación de la Televisión Digital Terrestre - TDT que, mediante un decodificador externo conectado a televisores antiguos o interno en modelos más recientes, posibilitó acceder a televisión en alta definición en el $80 \%$ del territorio nacional para el 2020, según cifras de MinTIC. Según la página tdtparatodos.tv el 31 de diciembre de 2021 es la fecha límite para la implementación de la TDT en el 100\% del territorio nacional, puesto que las emisiones analógicas se suspenderán. ${ }^{2}$

Otra situación que viene presentando transformaciones en el sector de las TIC, es el relacionado con la prestación de servicios móviles y de internet. Al respecto, la Comisión de Regulación de las Comunicaciones, señala que en el país se encuentran 8 empresas en-

1 Gaceta (2020). Sigue polémica por decreto que baja cuota de producciones nacionales en la tv, El País.com, Abril 26 de 2020, consultado el 11 de abril de 2021. Disponible en https:/www.elpais.com.co/cultura/gaceta/la-tv-colombiana-esta-rota-asi-va-la-polemicapor-el-decreto-que-baja-la-cuota-de-pantalla.html

2 Tdtparatodos.tv. 31 de diciembre de 2022 es la fecha límite para el cese de emisiones analógicas de televisión, consultado el 11 de abril de 2021. Disponible en https://www. tdtparatodos.tv/noticias/colombia-avanza-proceso-migracion-tdt 
cargadas de dicho servicio como lo son: Avantel, Claro, ETB, Éxito Móvil, Movistar, Tigo, Uffmovil y Virgin Mobile. Según el reporte de Opensignal publicado en enero de 2021, de las anteriores empresas Tigo se posicionó como la mejor empresa en ofrecer los servicios de conectividad al alcanzar 6 de los 7 reconocimientos que otorga esta mención superando a Claro, quien dominando el panorama en los últimos años. ${ }^{3}$

En este panorama, se presenta la irrupción de un nuevo competidor dentro del mercado de las telecomunicaciones llamado "Wom" que para el 2020 prometió consolidarse como una de las mejores empresas de conectividad del país. Según Chris Bannister, director de Wom para Colombia, se estima invertir más de un billón de dólares durante los próximos 5 años en cobertura de red, tecnología y servicio al cliente, sin embargo, entre las diferentes polémicas que ha presentado la llegada de este nuevo operador, el panorama de la competitividad es desalentador, puesto que Claro es el prestador de servicios móviles que más líneas acumula en el país con 31,2 millones de líneas, seguido por Movistar con 15, 9 millones y Tigo, con 11, 8 millones. ${ }^{4}$

\section{Análisis del año: La ficción de estreno nacional e iberoamericana en la TV abierta}

Tabla 1. Ficciones exhibidas en 2020 (nacionales e importadas; estreno, repeticiones y coproducciones).

\begin{tabular}{|c|c|}
\hline $\begin{array}{l}\text { TÍTULOS INÉDITOS NACIONALES } 8 \\
\text { TITULOS } \\
\text { Canal CARACOL- } 4 \text { Títulos } \\
\text { 1. Amar y Vivir (Telenovela) } \\
\text { 2. La Ley Secreta (Serie) } \\
\text { 3. El General Naranjo (Serie) } \\
\text { 4. La Venganza de Analía (Telenovela) }\end{array}$ & $\begin{array}{l}\text { TÍTULOS IMPORTADOS INÉDITOS OBITEL - } 4 \\
\text { TITULOS } \\
\text { Canal CARACOL } \mathbf{3} \text { títulos } \\
\text { 1. Cuna de Lobos (Telenovela-México) } \\
\text { 2. Imperio de Mentiras (Telenovela- México) } \\
\text { 3. La Usurpadora (Telenovela-México) } \\
\text { Canal RCN } 1 \text { títulos } \\
\text { 4. Te doy la Vida (Telenovela-México) }\end{array}$ \\
\hline
\end{tabular}

3 Portafolio (2021). ¿Cuál es hoy el operador con mejor internet móvil en Colombia?, 04 de febrero de 2021, consultado el 11 de abril de 2021. Disponible en https://www.portafolio.co/negocios/empresas/cual-es-el-operador-de-telefonia-con-mejor-internet-movil-encolombia-548832

4 El Tiempo (2020). Wom, el nuevo operador que llega a dinamizar la telefonía móvil, El Tiempo.com, 03 de noviembre de 2020, consultado el 11 de abril de 2021. Disponible en https://www.eltiempo.com/tecnosfera/novedades-tecnologia/wom-el-nuevo-operador-quellega-a-dinamizar-la-telefonia-movil-en-colombia-546711 


\begin{tabular}{|c|c|}
\hline $\begin{array}{l}\text { TÍTULOS INÉDITOS NACIONALES } 8 \\
\text { TITULOS } \\
\text { Canal 1- } 1 \text { Título } \\
\text { 1. Aníbal Sensación Velásquez (Telenovela) } \\
\text { Canal RCN -3 títulos } \\
\text { 2. Pa quererte (Telenovela) } \\
\text { 3. Confinados (Serie) } \\
\text { 4. Verdad Oculta (Serie) } \\
\text { COPRODUCCIONES - } 1 \text { TITULO } \\
\text { Canal } 1 \text {-1 títulos } \\
\text { 1. Decisiones (Serie) }\end{array}$ & $\begin{array}{l}\text { TÍTULOS REPETICIONES 35 TITULOS } \\
\text { 1. Allá te Espero (telenovela) } \\
\text { 2. Amor en Custodia (telenovela) } \\
\text { 3. Contra las Cuerdas (telenovela) } \\
\text { 4. Doña Bella (telenovela) } \\
\text { 5. En Tierras Salvajes (telenovela) } \\
\text { 6. Enfermeras (telenovela) } \\
\text { 7. La Traicionera (telenovela) } \\
\text { 8. Chepe Fortuna (telenovela) } \\
\text { 9. Cuando me Enamoro (telenovela) } \\
\text { 10. El Inútil (telenovela) } \\
\text { 11. Francisco el Matemático (telenovela) } \\
\text { 12. Soy tu Dueña (telenovela) } \\
\text { 13. Teresa (telenovela) } \\
\text { 14. } 3 \text { milagros (telenovela) } \\
\text { 15. Amor Sincero (telenovela) } \\
\text { 16. Diomedes Cacique de la Junta (telenovela) } \\
\text { 17. El Joe la Leyenda (telenovela) } \\
\text { 18. Hasta que la Plata nos Separe (telenovela) } \\
\text { 19. La Hija del Mariachi (telenovela) } \\
\text { 20. Los Reyes (telenovela) } \\
\text { 21. Yo soy Betty la Fea (telenovela) } \\
\text { 22. Abismo de Pasión (telenovela) } \\
\text { 23. Corazón Indomable (telenovela) } \\
\text { 24. El Cuerpo del Deseo (telenovela) } \\
\text { 25. La que no podia Amar (telenovela) } \\
\text { 26. Un refugio para el Amor (telenovela) } \\
\text { 27. Bellas Calamidades (telenovela) } \\
\text { 28. Cuna de Lobos } \\
\text { 29. La que no Podía Amar (telenovela) } \\
\text { 30. Lo que la Vida me Robó (telenovela) } \\
\text { 31. Rubi (telenovela) } \\
\text { 32. La Nocturna (telenovela) } \\
\text { 33. Pasión de Gavilanes (telenovela) } \\
\text { 34. Pedro el Escamoso (telenovela) } \\
\text { 35. Rafael Orozco el Ídolo (serie) } \\
\text { TOTAL DE TÍTULOS INÉDITOS } \\
\text { TOTAL DE TÍTULOS INÉDITOS OBITEL:4 } \\
\text { TOTAL DE TÍTULOS INÉDITOS (NACIONAL Y } \\
\text { OBITEL):12 }\end{array}$ \\
\hline
\end{tabular}

Fuente: OBITEL Colombia / Kantar Ibope Media Colombia

En 2020 el número de reprises (repeticiones) aumentó considerablemente frente a los títulos inéditos, en gran medida a causa de las regulaciones sobre cuota de pantalla de la producción nacional y que, ante la imposibilidad de grabación y producción, conllevó que 
algunas ficciones dejarán de emitirse al no poderse producir nuevos capítulos (caso $\mathrm{Pa}$ quererte) y se llenarán las parrillas televisivas con contenidos de otras épocas.

Tabla 2: La ficción de estreno en 2020: Países de origen

\begin{tabular}{|l|r|r|r|r|r|r|}
\hline \multicolumn{1}{|c|}{ País } & Títulos & \multicolumn{1}{c|}{$\%$} & $\begin{array}{r}\text { Capítulos/ } \\
\text { Episodios }\end{array}$ & \multicolumn{1}{c|}{ \% } & \multicolumn{1}{c|}{ Horas } & \multicolumn{1}{c|}{} \\
\hline NACIONAL (total) & $\mathbf{8}$ & $\mathbf{6 6 , 7}$ & $\mathbf{3 3 6}$ & $\mathbf{6 0 , 2}$ & $\mathbf{2 7 0 : 4 5 : 0 0}$ & $\mathbf{6 9 , 9}$ \\
\hline PAÍSES OBITEL (total) & $\mathbf{4}$ & $\mathbf{3 3 , 3}$ & $\mathbf{2 2 2}$ & $\mathbf{3 9 , 8}$ & $\mathbf{1 1 6 : 3 0 : 0 0}$ & $\mathbf{3 0 , 1}$ \\
\hline Argentina & 0 & 0,0 & 0 & 0,0 & $0: 00: 00$ & 0,0 \\
\hline Brasil & 0 & 0,0 & 0 & 0,0 & $0: 00: 00$ & 0,0 \\
\hline Chile & 0 & 0,0 & 0 & 0,0 & $0: 00: 00$ & 0,0 \\
\hline Colombia & 8 & 66,7 & 336 & 60,2 & $270: 45: 00$ & 69,9 \\
\hline Ecuador & 0 & 0,0 & 0 & 0,0 & $0: 00: 00$ & 0,0 \\
\hline España & 0 & 0,0 & 0 & 0,0 & $0: 00: 00$ & 0,0 \\
\hline $\begin{array}{l}\text { EEUU (producción } \\
\text { hispánica) }\end{array}$ & 1 & 8,3 & 0 & 0,0 & $0: 00: 00$ & 0,0 \\
\hline México & 4 & 33,3 & 222 & 39,8 & $116: 30: 00$ & 30,1 \\
\hline Perú & 0 & 0,0 & 0 & 0,0 & $0: 00: 00$ & 0,0 \\
\hline Portugal & 0 & 0,0 & 0 & 0,0 & $0: 00: 00$ & 0,0 \\
\hline Uruguay & 0 & 0,0 & 0 & 0,0 & $0: 00: 00$ & 0,0 \\
\hline Venezuela & 0 & 0,0 & 0 & 0,0 & $0: 00: 00$ & 0,0 \\
\hline COPRODUCIONES (total) & $\mathbf{1}$ & $\mathbf{0 , 0}$ & $\mathbf{0}$ & $\mathbf{0 , 0}$ & $\mathbf{0 : 0 0 : 0 0}$ & $\mathbf{0 , 0}$ \\
\hline $\begin{array}{l}\text { Coproducciones } \\
\text { colombianas }\end{array}$ & $\mathbf{0}$ & $\mathbf{0 , 0}$ & $\mathbf{0}$ & $\mathbf{0 , 0}$ & $\mathbf{0 : 0 0 : 0 0}$ & $\mathbf{0 , 0}$ \\
\hline $\begin{array}{l}\text { Coproducciones entre países } \\
\text { Obitel }\end{array}$ & $\mathbf{0}$ & $\mathbf{0 , 0}$ & $\mathbf{0}$ & $\mathbf{0 , 0}$ & $\mathbf{0 : 0 0 : 0 0}$ & $\mathbf{0 , 0}$ \\
\hline TOTAL GENERAL & $\mathbf{1 2}$ & $\mathbf{1 0 0 , 0}$ & $\mathbf{5 5 8}$ & $\mathbf{0 , 0}$ & $\mathbf{3 8 7 : 1 5 : 0 0}$ & $\mathbf{1 0 0 , 0}$ \\
\hline
\end{tabular}

Fuente: OBITEL Colombia / Kantar Ibope Media Colombia

En cuanto a los países de origen, es evidente el crecimiento de las ficciones en coproducción y la mayor presencia de producciones colombianas, algo mediado en gran medida por la aplicación de la cuota de pantalla, que estuvo llena de producción nacional de otra época. 
Tabla 3: Formatos de la ficción nacional e Iberoamericana

\begin{tabular}{|c|c|c|c|c|c|c|c|c|c|c|c|c|}
\hline \multirow{2}{*}{ Formato } & \multicolumn{6}{|c|}{ Nacionales } & \multicolumn{6}{|c|}{ Ibero-americanos } \\
\hline & Títulos & $\%$ & $\mathbf{C} / \mathbf{E}$ & $\%$ & $\mathbf{H}$ & $\%$ & Títulos & $\%$ & $\mathbf{C} / \mathbf{E}$ & $\%$ & $\mathbf{H}$ & $\%$ \\
\hline Telenovela & 25 & 67,6 & 2946 & 83,0 & $2482: 00: 00$ & 75,3 & 21 & 60,0 & 2440 & 73,0 & $1854: 34: 48$ & 0,6 \\
\hline Serie & 12 & 32,4 & 604 & 17,0 & $815: 15: 48$ & 24,7 & 14 & 40,0 & 902 & 27,0 & $1249: 37: 00$ & 0,4 \\
\hline Miniserie & 0 & 0,0 & 0 & 0,0 & 0:00:00 & 0,0 & 0 & 0,0 & 0 & 0,0 & 0:00:00 & 0,0 \\
\hline Telefilme & 0 & 0,0 & 0 & 0,0 & 0:00:00 & 0,0 & 0 & 0,0 & 0 & 0,0 & $0: 00: 00$ & 0,0 \\
\hline Unitário & 0 & 0,0 & 0 & 0,0 & 0:00:00 & 0,0 & 0 & 0,0 & 0 & 0,0 & 0:00:00 & 0,0 \\
\hline Docudrama & 0 & 0,0 & 0 & 0,0 & $0: 00: 00$ & 0,0 & 0 & 0,0 & 0 & 0,0 & $0: 00: 00$ & 0,0 \\
\hline $\begin{array}{l}\text { Otros (soap } \\
\text { opera, etc) }\end{array}$ & 0 & 0,0 & 0 & 0,0 & 0:00:00 & 0,0 & 0 & 0,0 & 0 & 0,0 & 0:00:00 & 0,0 \\
\hline Total & 37 & 100,0 & 3550 & 100,0 & 3297:15:48 & 100,0 & 35 & 100,0 & 3342 & 100,0 & 3104:11:48 & 1,0 \\
\hline
\end{tabular}

Fuente: OBITEL Colombia/ Kantar Ibope Media Colombia

En el análisis de estrenos nacionales e iberoamericanos priman las telenovelas como protagonistas de la parrilla televisiva, principalmente a causa del protagonismo del reprise que refleja un momento histórico en el que este era el formato predominante en ficción y apenas empezaba a dibujarse el panorama dominante de las series en los últimos años.

Tabla 4: Los diez títulos más vistos en televisión abierta

\begin{tabular}{|c|l|c|c|c|l|l|c|c|}
\hline \multicolumn{2}{|c|}{ Título } & Canal & Productora & Formato/género & $\begin{array}{l}\text { No. de } \\
\text { cap/ep } \\
\text { (en 2020) }\end{array}$ & $\begin{array}{l}\text { Franja } \\
\text { horaria }\end{array}$ & Rating & Share \\
\hline 1 & $\begin{array}{l}\text { Pasión De } \\
\text { Gavilanes }\end{array}$ & Caracol & Caracol & Telenovela & 188 & Prime & 14,26 & 43,14 \\
\hline 2 & $\begin{array}{l}\text { La venganza de } \\
\text { Analía }\end{array}$ & Caracol & Caracol & Telenovela & 53 & Prime & 12,82 & 36,22 \\
\hline 3 & Amary vivir & Caracol & Caracol & Telenovela & 69 & Prime & 11,85 & 34,58 \\
\hline 4 & $\begin{array}{l}\text { Pedro el } \\
\text { escamoso }\end{array}$ & Caracol & Caracol & Telenovela & 160 & Prime & 11,30 & 40,88 \\
\hline 5 & Pa Quererte & RCN & RCN & Telenovela & 137 & Prime & 11,26 & 18,87 \\
\hline 6 & Enfermeras & RCN & RCN & Telenovela & 159 & Prime & 10,53 & 22,59 \\
\hline 7 & $\begin{array}{l}\text { Rafael Orozco, El } \\
\text { Idolo }\end{array}$ & Caracol & Caracol & Serie & 90 & Prime & 10,32 & 36,46 \\
\hline 8 & $\begin{array}{l}\text { El General } \\
\text { Naranjo }\end{array}$ & Caracol & $\begin{array}{c}\text { Fox } \\
\text { Telecolombia }\end{array}$ & Serie & 52 & Prime & 9,86 & 36,78 \\
\hline 9 & Amor Sincero & RCN & RCN & Telenovela & 81 & Prime & 9,17 & 24,41 \\
\hline 10 & 3 Milagros & RCN & RCN & Serie & 70 & Prime & 8,3 & 24 \\
\hline
\end{tabular}

Fuente: OBITEL Colombia / Kantar Ibope Media Colombia 
Es evidente la alta presencia de reprises como los grandes protagonistas en el rating, lo que también permitió que la telenovela volviera a tener relevancia y posicionarse como el formato dominante. Entre las ficciones de estreno no obstante vuelve a ser central el papel principal de Caracol con el posicionamiento de La venganza de Analía por encima de $\mathrm{Pa}$ Quererte y Enfermeras, que fueron en conjunto las únicas ficciones de estreno junto con El general Naranjo en obtener una posición entre los 10 más vistos del 2020.

Tabla 5: Perfil de audiencia de los diez títulos mas vistos: género, edad, nivel socio económico

\begin{tabular}{|c|c|c|c|c|c|c|c|c|c|c|c|c|}
\hline & \multirow{2}{*}{ Títulos } & \multirow{2}{*}{ Canal } & \multicolumn{2}{|c|}{ Género \% } & \multicolumn{3}{|c|}{ Nível Socioeconómico \% } & \multicolumn{5}{|c|}{ Franjas De Edad \% } \\
\hline & & & Mujeres & Hombres & $\mathbf{A B}^{*}$ & $\mathrm{C}^{*}$ & $\mathbf{D E}^{*}$ & $\begin{array}{l}4 \mathrm{~A} \\
11 *\end{array}$ & $\begin{array}{c}12 \mathrm{~A} \\
17^{*}\end{array}$ & $\begin{array}{c}18 \mathrm{~A} \\
24^{*}\end{array}$ & $\begin{array}{c}25 \mathrm{~A} \\
34^{*}\end{array}$ & $50+*$ \\
\hline 1 & $\begin{array}{l}\text { Pasión de } \\
\text { Gavilanes }\end{array}$ & Caracol & 48,48 & 38,92 & 42,86 & 48,01 & 47,40 & 118,07 & 76,6 & 84,49 & 85,8 & 39,6 \\
\hline 2 & $\begin{array}{l}\text { La Venganza } \\
\text { de Analía }\end{array}$ & Caracol & 25,87 & 20,31 & 48,25 & 50,46 & 35,64 & 46,11 & 26,7 & 32,76 & 43,48 & 22,6 \\
\hline 3 & Amar y Vivir & Caracol & 36,67 & 32,94 & 33,12 & 39,56 & 38,76 & 6,99 & 11,2 & 4,19 & 5,15 & 5,7 \\
\hline 4 & $\begin{array}{l}\text { Pedro El } \\
\text { Escamoso } \\
\end{array}$ & Caracol & 44,95 & 40,76 & 31,51 & 44,71 & 48,59 & 107,18 & 75,2 & 84,27 & 82,6 & 41,9 \\
\hline 5 & Pa Quererte & $\mathrm{RCN}$ & 15,43 & 14,49 & 19,00 & 16,47 & 11,35 & 17,97 & 17,97 & 17,97 & 17,97 & 17,97 \\
\hline 6 & Enfermeras & $\mathrm{RCN}$ & 16,03 & 10,92 & 10,19 & 11,27 & 16,22 & 34,95 & 36,6 & 25,4 & 29,78 & 10,7 \\
\hline 7 & $\begin{array}{l}\text { Rafael } \\
\text { Orozco, el } \\
\text { ídolo } \\
\end{array}$ & Caracol & 41,26 & 34,19 & 31,00 & 40,10 & 42,92 & 96,88 & 59,6 & 76,38 & 65,92 & 36,3 \\
\hline 8 & $\begin{array}{l}\text { El General } \\
\text { Naranjo } \\
\end{array}$ & Caracol & 33,06 & 32,28 & 37,25 & 39,23 & 34,84 & 62,37 & 41,8 & 50,09 & 55,69 & 36,2 \\
\hline 9 & Amor Sincero & $\mathrm{RCN}$ & 24,03 & 18,97 & 29,44 & 20,15 & 7,64 & 20,51 & 24,41 & 24,78 & 20,31 & 21,2 \\
\hline 10 & 3 Milagros & $\mathrm{RCN}$ & 24,83 & 19,41 & 7,24 & 18,32 & 29,42 & 24,03 & 30,5 & 41,67 & 22,25 & 17,8 \\
\hline
\end{tabular}

Fuente: OBITEL Colombia / Kantar Ibope Media Colombia

Se observa un aumento de espectadores de todas las edades y condición económica. Esto está dado al aumento de las horas en las que se permanece en la casa por las condiciones de aislamiento preventivo y poco interés por realizar otras actividades diferentes a seguir la trama de alguna telenovela emitida en otro momento en el pasado. 


\section{Monitoreo VoD 2020}

El 2020 tanto para Colombia, como para otros países, fue un año coyuntura a causa de la emergencia sanitaria del Covid-19. Lo anterior, sumado a la alta demanda de conectividad, ha conllevado a transformaciones en el consumo de contenido, pues se han reemplazado la forma tradicional de ver, primando el acceso a otras plataformas de entretenimiento audiovisual. De esta forma las audiencias digitales y los nuevos patrones de consumo se han incrementado gracias a la pandemia, la cual ha dinamizado y fomentado aún más el uso de plataformas Streaming (Tuñon, 2021).

De tal manera, un modo de entretención como alternativa al confinamiento por la pandemia fue principalmente el acceso a las plataformas streaming. Es así que dentro de lo más visto se encuentran los realities, concursos, drama y comedia (SEMANA, 2020).

\subsection{Mercado de plataformas de VoD}

Con el propósito de realizar un paneo sobre la magnitud del mercado VoD en Colombia, es necesario comprender que inevitablemente la pandemia ha generado en el país, y en Latinoamérica, un incremento de la demanda de contenido Streaming. De acuerdo al estudio de Sherlock Communications (2020), en el que se hallan las percepciones de 3.000 consumidores de países como Brasil, México, Argentina, Perú y Chile, incluido Colombia. Este último representó un $43 \%$ de encuestados que dijeron ver en el Streaming una de las mejores alternativas para la cuarentena. Es de esta manera que Colombia representa el 36\% de consumidores que dicen estar insatisfechos con los canales locales, por lo que el $20 \%$ de colombianos señalaron haberse suscrito a dos plataformas distintas y un $24 \%$ son nuevos suscriptores a plataformas VoD. 
Por otro lado, si se considera que una de las razones por lo que los consumidores prefieren servicios VoD o servicios OTT, Disney + el lanzamiento como ya se mencionó más llamativo del año pasado, ofreció una gama de contenidos como Lucasfilm y Marvel con programas populares como The Mandalorian, Muppets Now, entre otros, por su parte HBO Max tuvo un lanzamiento con un perfil más bajo, logrando un aumento al presentar programas originales como Justice League de Zack Snyder y The Flight Attendant (ZEMOGA, 2020).

\subsection{Análisis del VoD en 2020: la ficción de estreno nacional e iberoamericana}

Teniendo en cuenta que una de las plataformas más populares luego de la pandemia por Covid-19 fue Netflix, se logró hallar que los contenidos más vistos en Colombia fueron los realities Jugando con Fuego, El iso es Lava y El Amor es Ciego, esto sumando contenidos de acción como Misión de Rescate, La vieja Guardia y Proyecto Power. Además los colombianos vieron más contenido coreano que en 2019. En los inicio de abril el drama más visto en el país fue Milagro en la Celda. Respecto a la comedia Chichipatos fue la más popular a la par de El Halloween de Hubie y Amor de calendario. Finalmente los títulos de fantasía más vistos fueron Siempre Bruja y Locke \& Key. En conclusión, de acuerdo a Netflix, el 2020 en Colombia arrojó que el consumo de realities y género de acción se duplicó, la visualización de contenido coreano, turco y género de fantasía se triplicó, y el consumo del género de Romance aumentó en casi un 300\% (INFOBAE, 2020).

Por tal razón se examinan en la tabla 6 , las ficciones nacionales e iberoamericanas exhibidas en 2020 en sistemas los sistemas VoD más populares y con mayor número de participación en producciones de entretenimiento Streaming. 
Tabla 6. Ficciones nacionales e iberoamericanas exhibidas en 2020 en sistemas de VoD

\begin{tabular}{|c|c|c|}
\hline $\begin{array}{l}\text { TÍTULOS } \\
\text { NACIONALES DE } \\
\text { ESTRENO }\end{array}$ & $\begin{array}{l}\text { TÍTULOS } \\
\text { IBEROAMERICANOS DE } \\
\text { ESTRENO }\end{array}$ & COPRODUCCIONES \\
\hline $\begin{array}{l}\text { Netflix - No títulos } \\
\text { nacionales } \\
\text { 1. Loco por vos (Película) } \\
\text { 2. Chichipatos (Película) } \\
\text { 3. Amary yivir (Serie) } \\
\text { 4. Siempre bruja } \\
\text { temporada } 2 \text { (Serie) } \\
\text { 5. El robo del siglo (Serie) } \\
\text { Caracol Play - No títulos } \\
\text { nacionales } \\
\text { 1. La venganza de Analia } \\
\text { (Serie) } \\
\text { 2. La nocturna } 2 \text { (Serie) }\end{array}$ & $\begin{array}{l}\text { Netflix - No títulos } \\
\text { iberoamericanos } \\
\text { 1. El hoyo (Película - España) } \\
\text { 2.Hogar (Película - España) } \\
\text { 3. El silencio del pantano } \\
\text { (Película - España) } \\
\text { 4. El practicante (Película - } \\
\text { España) } \\
\text { 5. Buenos días, Verónica (Serie } \\
\text { - España) } \\
\text { 6. El amor es ciego (Reality- } \\
\text { chile) } \\
\text { 7.Jugando con fuego (Reality- } \\
\text { USA) } \\
\text { 8. El piso es lava (Realty-USA) } \\
\text { 9. El Halloween de Hubie } \\
\text { (Película - USA) } \\
\text { 10. La vieja guardia (Película - } \\
\text { USA). } \\
\text { 11. Esta mierda me supera } \\
\text { (Serie - USA) } \\
\text { 12. Proyecto power (Película - } \\
\text { USA) } \\
\text { 13. Maldita ( Serie - USA) } \\
\text { 14. Locke \& Key (Serie- USA) } \\
\text { Claro TV - No títulos } \\
\text { iberoamericanos } \\
\text { 1. Reto Tokio } 2020 \text { (Serie - } \\
\text { México) } \\
\text { HBO GO - No títulos } \\
\text { iberoamericanos } \\
\text { 1. Murder on middle beach } \\
\text { (Serie - USA) }\end{array}$ & $\begin{array}{l}\text { Netflix }-\mathbf{N}^{\circ} \text { títulos } \\
\text { 1. Shark Tank temporada } 3 \\
\text { (Serie-USA y México) }\end{array}$ \\
\hline Total: 7 & Total: 16 & Total: 1 \\
\hline
\end{tabular}

Fuente: OBITEL Colombia 
De un total de 24 series estrenadas en 2020 en plataformas VoD, se logró evidenciar que se estrenaron siete series nacionales: cinco en Netflix, siendo El robo del siglo una de las más populares en Iberoamérica y dos series estrenadas en Caracol Play. Los títulos de estrenos Iberoamericanos fueron 15: de los que 13 fueron producidos por Netflix, uno por Claro Tv y uno Por HBO GO. Respecto a coproducciones entre Colombia y otros países no se hallaron resultados de estrenos, mientras que se halló el estreno de una serie coproducida entre USA y México.

Por consiguiente, las series estrenadas y más vistas en Colombia permiten hallar que los realitiy shows son una nueva manera de consumo en plataformas VoD. En la tabla 7, se exponen los estrenos en 2020 en VoD por país de origen con el fin de evaluar el nivel de participación de los países OBITEL.

Tabla 7. Estrenos en 2020 en VOD: países de origen

\begin{tabular}{|l|c|c|}
\hline \multicolumn{1}{|c|}{ País } & Títulos & $\mathbf{\%}$ \\
\hline NACIONAL TOTAL & $\mathbf{7}$ & $\mathbf{3 0 , 4 3 \%}$ \\
\hline PAÍSES OBITEL TOTAL & $\mathbf{1 6}$ & $\mathbf{6 9 , 5 6}$ \\
\hline Argentina & 0 & 0 \\
\hline Brasil & 0 & 0 \\
\hline Chile & 1 & $4,34 \%$ \\
\hline Colombia & 7 & $30,43 \%$ \\
\hline Ecuador & 0 & \\
\hline España & 5 & $21.73 \%$ \\
\hline USA & 9 & $39,13 \%$ \\
\hline México & 1 & $4,34 \%$ \\
\hline Perú & 0 & 0 \\
\hline Portugal & 0 & 0 \\
\hline Uruguay & 0 & 0 \\
\hline Venezuela & 0 & 0 \\
\hline COPRODUCCIONES TOTAL & $\mathbf{1}$ & $\mathbf{4 , 3 4 \%}$ \\
\hline Coproducciones colombianas & 0 & \\
\hline Coproducciones entre países OBITEL & 1 & $4,34 \%$ \\
\hline TOTAL GENERAL & $\mathbf{2 3}$ & $\mathbf{1 0 0}$ \\
\hline
\end{tabular}

Fuente: OBITEL Colombia 
En la tabla 7 se hace evidente que la participación del país posee un porcentaje importante en la producción de contenido para plataformas $\mathrm{VoD}$, lo que permite reconocer la expansión de dichas plataformas en Iberoamérica. También se logró identificar que para el 2020 solo México y USA trabajaron en una coproducción para la región.

\section{Ficción y participación de las audiencias en entornos digitales}

En medio de la pandemia, en Colombia se promulga el Decreto 516 del 04 de abril del 2020 instaurada por el Ministerio de Tecnologías de la Información y las Comunicaciones TIC, por el cual se adoptan medidas para la prestación del servicio de televisión abierta radiodifundida, en el marco del Estado de Emergencia Económica, Social y Ecológica del COVID 19, con ello, se reduce la programación nacional en horario televisivo, a través de la mitad del número de horas mínimo que deben emitir los canales en su parrilla de programación; con lo anterior, los canales de televisión nacional de índole privado, que acaparan la mayoría de las audiencias, dejan de producir contenido actual para lo cual, proponen y efectúan la repetición de programas de ficción producidas hace dos décadas como la telenovela Pedro el Escamoso del año 2001. De igual manera, ante la falta de producción de ficción actual, se han realizado creaciones emergentes que son independientes de las empresas productoras de contenido, las cuales se reproducen o transmiten por plataformas de acceso abierto como YouTube, un ejemplo de ello, es la web serie colombiana "Aisla2 en cuarentena." Estos dos ejemplos son justamente los que se tomarán en cuenta para contemplar el análisis acerca de los modos en los que fue posible, por el lado del reprise generar condiciones para una interacción con la audiencia en medio de una especie de normalidad de la digitalización de la cotidianidad y, por otro lado, la aparición de 
nuevas apuestas desde el contexto mismo de la pandemia Propuestas de expansión digital.

Pedro el Escamoso, telenovela transmitida por Caracol Televisión, contiene 327 episodios con una duración aproximada de dos años, desde el 19 de abril del 2001 a su última emisión el 21 de febrero del 2003; para la actualidad su retransmisión se realiza a partir de octubre del 2020 vía televisión de señal abierta, que se expande al escenario digital desde una narrativa transmediática como las entrevistas hacia los actores en portales web, donde permiten visualizar un lapso comparativo de sus representaciones antiguas con sus cotidianidades y actividades actuales; capítulos completos en secuencia o intermitencia en redes sociales como YouTube o Facebook; marketing digital de la telenovela; representaciones del personaje en mensajería instantánea como gif animados o stickers; videos live en redes sociales o la espacialización de la banda sonora de la telenovela, el Pirulino, a plataformas como Spotify o YouTube.

En este orden de ideas, la telenovela se extiende a redes sociales donde se puede hallar con facilidad la búsqueda de capítulos, sin la necesidad de seguir una narrativa secuencial, lo que permite ubicar puntualmente los capítulos a desear o el adelanto de aspectos de la misma trama. En este escenario, la ficción se ubica en varios de los servicios OTT (Over- The- Top) que comprende contenidos, servicios o aplicaciones para los usuarios, entre estos Spotify, en mensajería instantánea como WhatsApp y en redes sociales como Tik Tok, Instagram, Twitter, YouTube y Facebook.

Así pues, en estas extensiones digitales se refleja o simboliza el personaje principal de la ficción, Pedro Coral Tavera, interpretada por el actor colombiano Miguel Varoni, quien es un hombre aproximadamente de 32 años con características propias de un joven pueblerino que llega a la Capital del país en búsqueda de oportunidades laborales, donde se ubica como conductor en una empresa de importaciones llamada Freydell y se enamora de su jefe; es así que, la producción 
de la ficción incorpora elementos particulares del pueblo que se transforman en un posible espacio identitario de nación, donde la narrativa de la ficción involucra tradicionalidades o cotidianidades populares que representan situaciones, celebraciones o perfiles característicos de las costumbres de una comunidad en particular, como lo son los reinados populares, la camiseta de la selección Colombia, el apoyo a la hinchada del equipo de fútbol, dialectos y la construcción de frases particulares del personaje o de índole coloquial, que se han vuelto virales como masimo, mompirris, escamoso, fantoche, sagrado rostro, al peluche, entre otros.

\section{Interactividad social}

Desde el punto de vista de las audiencias, en el servicio de mensajería instantánea WhatsApp los diferentes usuarios crean imágenes estáticas o animadas, sobre la ficción y el personaje del mismo, que son referencia comunicativa y conllevan un mensaje implícito o con palabras claves propias del personaje (masimo, sagrado rostro, mompirris, etc.) de esta manera, se evidencia al personaje como icono comunicativo en los gifs que complementan el mensaje a emitir; así mismo, las audiencias son creadoras de imágenes divertidas como los memes en relación al personaje Pedro Coral y que se viralizan no solo en WhatsApp, sino en redes sociales como Facebook e Instagram. De esta manera, las audiencias desde la extensión digital son prosumidores, es decir, son consumidores y creadores de contenido de la ficción realizada hace dos décadas, presentándose así, una interactividad entre los usuarios que referencian la telenovela.

Además, desde redes sociales como Tik Tok se observan variedad de videos en relación a la trama, donde los usuarios interactúan con la ficción desde diferentes escenarios, entre estos, suben videos de escenas puntuales cómicas o pintorescas de la telenovela que impactan o se relacionan con la cotidianidad de la sociedad; del mismo 
modo, los usuarios recrean a los personajes de la ficción en muñecos con las características físicas de los actores; así mismo, las audiencias personifican el personaje principal, utilizando ropa o pelucas idénticas para bailar como lo hace Pedro el escamoso con la reconocida canción “El pirulino"; también la creación de videos actuales donde el actor, Miguel Varoni, baila igual que el personaje que imitaba hace dos décadas. En relación a las redes sociales como Facebook, Instagram o Twitter se hallan grupos o perfiles de los usuarios de la novela, muchos de estos creados por el Canal Caracol, donde se comparten capítulos, adelantos expectativos, opiniones y memes de la novela. Junto con ello, se potencializó los seguidores de los actores que interpretaron los personajes de la ficción, en sus redes sociales.

\section{Producciones de ficción emergente}

En Colombia, en medio del confinamiento obligatorio, los medios de comunicación y la prestación de servicio de señal abierta constriñó la nula producción de ficción actual, para lo cual, actores y actrices colombianos ejecutaron un proyecto independiente de los medios o empresas privadas, a través de plataformas de acceso abierto como la red social YouTube, ejemplo de ello, es la web serie Aisla2 en cuarentena.

Dicha historia, refleja momentos de los nuevos hábitos que la sociedad construyó a partir del confinamiento obligatorio, como los encuentros o citas virtuales, trabajo en plataformas digitales y sensaciones o emociones como la soledad, la depresión, la alegría, la ansiedad que muchas personas vivieron a partir de la cuarentena. Evidenciando con ello, elementos y herramientas de medios digitales para subsistir y responder a las necesidades de los encuentros sociales que se realizaban de manera física o presencial.

En relación con las interacciones de los diferentes usuarios de la web serie, desde el canal de YouTube Aisla2 en cuarentena, se ob- 
servan comentarios positivos hacia la serie, sin embargo, en la medida que salían los capítulos su audiencia fue disminuyendo, tanto así que el primer capítulo cuenta con 11.683 visualizaciones y 436 likes, en comparación con el décimo y último capítulo que contiene 3416 visualizaciones y 163 likes, lo anterior permite evidenciar la poca publicidad o marketing digital que se realizó de la web serie, ya que no es producida por los medios de índole privado que acaparan la mayoría de las audiencias.

\section{Lo más destacado del año}

Las dinámicas sociales antes y después de la pandemia han cambiado en atención a la situación actual por la que se encuentra atravesando el mundo, la aparición de una amenaza para la salud (el COVID-19), que en consecuencia ha generado alteraciones en los hábitos y comportamientos de los individuos. Los nuevos hábitos sociales que iniciaron como mecanismos de protección, hoy en día hacen parte de la cotidianidad; referirnos a confinamientos, aislamientos y cuarentenas, ya no son términos novedosos, por el contrario, desde la llegada del virus hacen parte de nuestra normalidad o, como actualmente se conoce, "la nueva normalidad".

El antes de la pandemia ofrecía gran variedad de producciones con diferentes temáticas, entre esas, ficciones que dibujaban problemáticas sociales de la actualidad colombiana, como: la Venganza de Analía, Pa`Quererte y Enfermeras, en la primera producción, se pretendía mostrar casos de corrupción vinculados a un ámbito social como la política; la segunda producción, enseñaba una realidad que no es ajena a ningún estrato o círculo social, como es la dificultad en la construcción de la unidad familiar, desde el punto de vista del vínculo afectivo entre padres e hijos y las obligaciones emanadas de este vínculo; en la tercera producción, se ponía en evidencia otras situaciones 
que también aquejan a los colombianos como las barreras al acceso a la salud e inestabilidad laboral de los trabajadores de la salud.

En cuanto a las producciones El General Naranjo y Betty la $F e a$, probablemente, no lograron consolidarse en el rating debido a que su contenido era más denso y de poca acogida para el nuevo público, ya que sus temáticas se enmarcan en contextos más singulares dirigidas a un público específico.

En relación con las producciones de Pedro el Escamoso y $\mathrm{Pa}$ sión de Gavilanes, debido a las restricciones sociales y a los nuevos acontecimientos, estas producciones que abordan contenidos apacibles resultan ser espacios de entretenimiento familiar incluyente, dirigido a un público amplío, de fácil entendimiento que han logrado rescatar audiencias que en otros tiempos hubiese sido difíciles de cautivar. Todo ello porque están desarrolladas con tramas y lenguajes jocosos y agradables a partir de los cuales se narran situaciones lejanas de la realidad, que cautivan al espectador por ser dramas inverosímiles. Por otra parte, no es menos importante destacar que existen otros factores que han afectado en la programación actual desde la pandemia y es la pausa obligada que tuvieron las nuevas producciones entre realities, dramatizados y telenovelas, por ejemplo, para los canales $\mathrm{RCN}$ y Caracol, que por tiempos de pandemia se vieron obligados a detener sus producciones.

\section{Tema del año: La Ficción en tiempos de pandemia en Colombia}

En tiempos extraordinarios como los que se viven actualmente a raíz de la pandemia provocada por el COVID 19, en el mundo entero no solo surgen situaciones insospechadas y difíciles de asimilar sino que muchos de los procesos que definen el acontecer social parecieran revestirse de un significado diferente o mucho más complicado de lo que solía ser. El mundo ha cambiado, está cambiando para bien o para mal, y la única opción que queda es la de enfrentar con realismo 
este reto tan dramático que sigue prolongándose en el tiempo y revistiéndose de múltiples facetas que siguen sorprendiéndonos. Sobra decir que en este contexto de profunda inestabilidad e incertidumbre en todos los aspectos de la vida social, también los medios masivos, la televisión y todo el componente de la ficción que circula a través de este dispositivo, se enfrentan en parte a una crisis y en parte a decisiones tanto de tipo económico como de producción para afrontar el día a día y mantener o robustecer su contacto con las audiencias.

Sumidos desde hace más de un año en esta drástica alteración del funcionamiento "normal" de la sociedad debido al impacto de la pandemia, muy pronto comenzó a hacerse evidente una especie de contradicción entre el proseguir la actividad económica de forma regular para garantizar el buen funcionamiento y el abastecimiento de los bienes y servicios necesarios para tal efecto, y, por otro lado, el llamado a proteger la salud y la vida de las gentes, a educarlas en un conjunto de hábitos y valores en torno a la prevención y el cuidado individual y colectivo. Esta paradoja que inicialmente pareció algo pasajero y susceptible de soluciones negociadas entre ambos factores, muy pronto se convirtió en países como el nuestro, caracterizados por una debilidad económica y una fragilidad histórica del Estado y la política social, y así mismo por la abundancia de la informalidad, la pobreza y la exclusión de amplias capas de la población, se convirtió en el drama del día a día y en el tema reiterado hasta el extremo por el discurso permanente de los medios masivos, especialmente por la televisión y por la presencia y capacidad de influencia cada vez mayor de las redes sociales.

Tal como se puede ilustrar a raíz de balances y declaraciones del sector de la industria audiovisual el impacto negativo de la pandemia significó prácticamente un paro generalizado en este sector productivo, clave en el funcionamiento de la sociedad. El régimen de aislamiento, cuarentenas y demás medidas restrictivas para la movilidad y el encuentro de grupos, se tradujo en una atmósfera de pasividad 
y enorme dificultad para producir y cambiar contenidos, formatos y programación con el ritmo acostumbrado, además de la crisis financiera implicada en ese corto circuito de la productividad.

Fuera de los dramas personales de individuos vinculados al medio, así como de pequeñas y grandes productoras ante la crisis mencionada, también es cierto que esta industria encontró una manera muy particular de sostenerse y proseguir en su labor cotidiana: de alguna manera las trágicas noticias de cada día en materia de enfermedad, cifras, muertes, contagios y recuperados, de pronósticos rayanos entre el pesimismo y un mesurado optimismo, se convirtieron en la oportunidad de negocio y también de entretenimiento para implementar un discurso continuo e ininterrumpido acerca del heroísmo de sobrevivir frente a una pandemia tan devastadora como suele representársela en el discurso mediático.

El primer eje de esta programación televisiva en tiempos de pandemia ha estado anclado en la abundancia de informativos desde el amanecer hasta el anochecer con lo que la televisión, por efecto de la permanencia de millones de personas en sus hogares, ha retornado, ha vuelto a ser esa especie de compañía del diario vivir, esa ventana a través de la cual el ciudadano, bastante aislado en el encierro, se informa de la realidad mundial y nacional, lo que por la convergencia tecnológica y mediática de los actuales sistemas de información se convierte en el discurso oficioso que debe ser atendido para sentirse "informado", esto es, "para sentirse participe de la problemática que enfrenta la humanidad".

Sobra decir que el tono de ese informativo continuo es admonitorio, repetitivo y centrado en todos los efectos adversos de la enfermedad y del comportamiento ciudadano como el factor determinante de la evolución del virus, frente a lo cual el Estado y sus instituciones se muestran como los garantes del orden, de la salubridad y del cuidado de la población. Las causas que originan muchos de los "malos comportamientos" de sectores de la población, en alusión a los secto- 
res mas pobres y excluidos de la pirámide social, por la informalidad laboral que padecen no pueden quedarse en sus "hogares", esas causas pasan inadvertidas en el discurso y no aparecen como el problema que representan y que deberían obrar como aglutinador no solo de consensos sino de soluciones reales por parte del gobierno de turno.

En contraposición funcional a esa tensión diaria de asumir el peso de los hechos, el drama y la tragedia en que se sumen el país y sus regiones, y en el que la gente es apenas un espectador intimidado, angustiado, incapaz y aislado, ante el temor generalizado por el eventual contagio y por un mañana plagado de incertidumbre, en medio del estrés de ese aislamiento continuo que ya parece interminable y que suele representarse como otra pandemia pavorosa, la programación televisiva, estancada debido a la crisis productiva del sector, ha echado mano de un recurso que a todas luces resultó de un valor simbólico y cultural incalculable: la abundancia de reprises en las franjas prime time, que se convierten en el recurso apropiado para hacer una catarsis en las audiencias, para ofrecer el mensaje suave y estimulante, el espacio para el relax y la sana diversión familiar, y también los contenidos obsequiosos con los cuales el consumidor de esta industria cultural puede convivir evocando mejores tiempos y alimentando la esperanza de que muy pronto las cosas cambiaran, retornarán a la normalidad y todo volverá a empezar de nuevo.

No obstante la situación de dificultad que se ha señalado en relación con la industria audiovisual en el país a raíz de la pandemia, también es cierto, y es además muy importante, que a pesar de la pandemia misma el mercado audiovisual en Colombia se está reconfigurando debido a la expansión y llegada de las grandes plataformas trasnacionales que dominan el sector, lo que ha implicado tanto alianzas con canales y programadoras nacionales así como pujas por obtener los mayores y mejores tiempos en el medio televisivo, lo cual quedó registrado en el debate y conflicto que se dio recientemente a raíz de la famosa "cuota de pantalla". 
En Colombia es claro que asistimos de tiempo atrás a una dura competencia entre los canales privados por el predominio y control del medio televisivo, a lo cual se suma la llamada de más competidores extranjeros, plataformas y sistemas de streaming, que al intensificar la lucha por audiencias y mayores recursos económicos y tecnológicos acaban por fortificar el mercado y mantener vigente la industria y el medio a expensas de un mayor consumo y, por ende, de una mayor incidencia en cuanto a representatividad y aceptación de sus mensajes y contenidos por parte de los públicos. Para ilustrar esta situación valga la pena mencionar la alianza entre Netflix y Caracol, lo que le permitió al primero dominar en este país la oferta de contenidos de ficción tanto en televisión como por demanda (caso Pasión de Gavilanes), de modo que el segundo inundó dicha plataforma con sus propias producciones centradas en series y narconovelas y en realizaciones melodramáticas asimiladas a distintos aspectos emocionales, afectivos y de idiosincrasia regional y nacional en los que los amplios públicos se encuentran, se identifican y disfrutan con dichas representaciones (casos Escobar el Patrón del mal, La ley secreta, La reina del Flow, entre otros).

En este nuevo escenario mediático televisivo resulta claro que seguimos asistiendo a una reconfiguración de los agentes que participan a todo lo largo del proceso de creación, producción, distribución y circulación de contenidos que inundan y dominan el mercado audiovisual nacional. Se trata de las alianzas y otros mecanismos que facilitan la producción conjunta, tal como se señaló antes, así como la emergencia de formas productivas por medio de las cuales tanto las grandes plataformas como los canales y programadoras nacionales buscan acomodarse en las actuales parrillas y formatos de oferta audiovisual para mantener y ampliar su cuota de presencia, e influencia y de rentabilidad económica y simbólica. Tal es el caso de la exitosa fórmula explotada por Netflix con Dynamo (productora nacional) en la realización de El robo del siglo, la cual ofreció una alternativa a la 
elaboración de contenidos con los grandes canales privados colombianos, así como también los acuerdos vigentes entre programadoras nacionales y canales de pago internacionales como FOX y HBO. Esto ratifica la presencia de un panorama diverso en la producción de ficción televisiva para los sistemas multipantalla en crecimiento en la nación y ayuda a dar cuenta de las fuertes tensiones que sobrevinieron con el debate legislativo en torno a la cuota de pantalla de la producción enteramente nacional en prime time.

Para referirnos en este apartado al lugar y significado de la televisión pública en el entorno audiovisual colombiano tenemos que registrar una situación que no es nueva, que hunde sus raíces en el tiempo, y de lo cual depende la caracterización que se puede realizar de nuestra televisión pública.

En primer lugar hay que subrayar el hecho de que la televisión pública en este y otros países latinoamericanos ha venido padeciendo década tras década una especie de cerco, de aislamiento y de recorte presupuestal y político, con lo que se ha afectado su rendimiento y su capacidad de tener mayor presencia e influencia en los diferentes públicos. Esto no es ajeno al afán privatizador que ha dominado la política de comunicación en el país en los últimos tiempos a efectos de favorecer la presencia de las grandes programadoras privadas y la llegada de la televisión de pago de origen transnacional, así como de las grandes plataformas proveedoras de contenidos en el sector audiovisual. Una televisión pública menguada presupuestalmente y muchas veces relegada a servicios de divulgación de contenidos de tipo educativo, raizal, cultural, que a pesar de su importancia para las diferentes comunidades quedan suscritos a las limitaciones estructurales de esta televisión pública nacional.

No obstante lo anterior, es preciso reconocer que existe en el país, alrededor de la televisión pública, una importante comunidad tanto de realizadores como de usuarios y facilitadores para que este medio pueda mantenerse activo y vigente y pueda seguir siendo una 
fuente enriquecedora de la diversidad social y cultural de la nación y de los intereses, principios y valores alrededor de los cuales se busca una identidad social integradora, un reconocimiento y una visibilización social y política de lo local, regional y de lo diferente, una integración de las comunidades a su pasado y a su presente reconfigurado con el recurso audiovisual. En este sentido es de destacar la construcción de la plataforma RTVC Play, un sistema de streaming que agrupa diversos tipos de producciones, pasando por la ficción y la incursión en formatos como la serie web (caso La de Troya), la narrativa transmedia (caso Paciente) y producciones en las que se realizan procesos de experimentación narrativa, sin dejar de lado el manejo de reprises de alto significado para el patrimonio cultural de la nación y de sus diversas comunidades (caso Crónicas de una generación trágica, Los pecados de Inés de Hinojosa, Dejémonos de vainas, etc).

De acuerdo con lo expuesto en este apartado nos parece relevante señalar que frente al recorte sistemático de recursos y apoyos por parte de los sucesivos gobiernos al sistema nacional de radio y televisión pública de Colombia, resulta ignominioso ver como el gobierno actual en su afán de "informar" equitativamente invierte una suma multimillonaria en la creación de un informativo oficial que solo puede resultar beneficioso para dicho gobierno y los intereses de los grupos que representa, y en cambio en desmedro de ofrecer a la población que no puede acceder a otras formas de uso del medio una información manipulada de acuerdo con el discurso institucionalizado. 